\title{
Tissue scurvy and the triad
}

\author{
Michael D. Innis
}

Retired Haematologist, Princess Alexandra Hospital, Brisbane, Australia

\section{Email address:}

micinnis@bigpond.com

\section{To cite this article:}

Michael D. Innis. Tissue Scurvy and the Triad. Clinical Medicine Research. Vol. 3, No. 4, 2014, pp. 94-95. doi: $10.11648 /$ j.cmr.20140304.13

\begin{abstract}
The Triad, characterized by bilateral retinal haemorrhages, diffuse cerebral haemorrhage and hypoxic ischaemic encephalopathy is conventionally thought to result from trauma caused by violently shaking a child by a parent or carer. The shaking is said to cause a to and fro movement of the brain in the skull leading to injury to the neurons, disruption of the cerebral veins and trauma to the retinal vessels. Vigorous shaking of a child has never been observed and an alternative explanation for these changes was sought. Here it is shown that Tissue Scurvy, an autoimmune disorder which has specific and consistent biochemical features of Hyperglycaemia and Liver Dysfunction as shown by abnormal Liver Function Tests, is the cause of the lesions. A child diagnosed as being the victim of the Shaken Baby Syndrome was tested for evidence of Tissue Scurvy and both Hyperglycaemia and Abnormal Liver Function were demonstrated. It is concluded that these results provide conclusive evidence that the Shaken Baby Syndrome is a form of Tissue Scurvy in which encephalopathy is caused by damage to neurons in the cervical spinal column causing hypoxia, which leads to ischaemic encephalopathy and the other features of the triad.
\end{abstract}

Keywords: Triad, Non-Accidental Injury, Shaken Baby Syndrome, Haemorrhage

\section{Case Report}

A mother was unwell throughout her pregnancy and was unable to take the vitamin tablets prescribed for her. There were 2 cats in the house and cats are known to carry the parasite Toxoplasma gondii which can infect the mother and be transferred to the foetus and cause Hepatitis. She has been on a gluten-free diet for many years and on $25^{\text {th }}$ January 2014 was found to be deficient in Vitamin D. She was tested for Toxoplasmosis and the test was negative.

A son was born by C-Section at 39 weeks gestation and weighed $6 \mathrm{lbs} 7 \mathrm{oz}$ and had Apgar scores of 8 and 9. He was breast fed for the $1^{\text {st }} 2$ weeks and then switched to Formula feeding. His progress was satisfactory.

At the age of $7^{1 / 2}$ months his father, who was in the house while the mother was at work, heard the infant whimper and went to check. He found the child had a wet nappy and while changing the nappy the infant made a convulsive movement with his right arm, his breathing became irregular, and he had a "strange disturbed look on his face". The father immediately phoned the mother and dialled 911.
The ambulance arrived and took him to the Medical Centre An examination, including Physical, Radiologic and Laboratory studies, was reported as showing:

\section{Clinical Investigations}

1. Bruises to the forehead, inconsistent with normal play.

2. History of bruises to the mandible per mother in the past consistent with forceful grab to jaw.

3. Metaphyseal/Corner fractures to right distal femur and tibia consistent with forceful twisting injury to extremity at knee and foot.

4. Closed Head Injury evidenced by :

Significant changes in the level of consciousness, subdural bleed and initial concern for shift.

5. Retinal haemorrhages.

Laboratory Investigations

Blood

1. ALT $86 \mathrm{U} / \mathrm{L} \quad$ Normal Range $0-55 \mathrm{U} / \mathrm{L}$

2. Glucose $\quad 40 \mathrm{mg} / \mathrm{d} / \mathrm{L} \quad 60-100 \mathrm{mg} / \mathrm{dL}$

3. BUN $\quad 2.0 \mathrm{mg} / \mathrm{dL} \quad 5-18 \mathrm{mg} / \mathrm{dL}$

4. Serum Albumin 3.2. g/dL $\quad 3.8-5.4 \mathrm{~g} / \mathrm{dL}$

5. Haemoglobin $\quad 10.1 \mathrm{~g} / \mathrm{dL} \quad 11.7-14 . \mathrm{g} / \mathrm{dL}$

6. Prothrombin Time $\quad 11.2 \mathrm{sec} \quad 9.1-12.0 \mathrm{sec}$ 


\section{PTT}

Urine

1. Glucose $300 \mathrm{mg} / \mathrm{dL}$

THE DOCTOR REPORTED THE FINDINGS WERE "ALL CONSISTENT MECHANISMS OF SHAKING (mother and father deny)."

\section{Discussion}

The normal Prothrombin Time helps to exclude Vitamin $\mathrm{K}$ deficiency as a cause of either the bruises or fractures[1,2] and the reduced PTT level indicates the presence of an Acute Phase Reactant which is a marker of Tissue damage and one need look no further than the Liver function tests to locate the damage. The elevated ALT and reduced Serum Albumin are recognized diagnostic features of Liver damage.

How was the damage caused is the next question - and this brings in the role of Tissue Scurvy.

Vitamin C deficiency, the cause of Scurvy, is well known for causing cell death leading to bleeding and fractures [3]. There are two recognized forms of Scurvy, both leading to cell death -Nutritional or Sea farer's Scurvy of yester year and Tissue Scurvy [4]. In Tissue Scurvy Vitamin C, although abundant in the blood, is unable to enter the cell to function effectively because of the lack of Insulin which is necessary to transfer Vitamin $\mathrm{C}$ from the blood into cell [5] and the result is cell death.

Tissue Scurvy is due to an autoimmune reaction which destroys the Beta cells of the Pancreas thereby reducing the supply of available Insulin and thus reducing or inhibiting the transfer of both Glucose and Vitamin C into the cell. The condition is easily recognized because the Blood shows increased levels of Glucose (Hyperglycaemia) and the Urine contains Glucose (Glycosuria). This is exactly what has occurred in this child as shown by the results of the Urine and Blood tests carried out on 15th August 2013.

Intracellular Vitamin $\mathrm{C}$ is necessary for the production of Collagen, the substance forming part of the wall of the blood vessels and the ground substance of bone.

The fractures and haemorrhages in children with Tissue Scurvy is explained by the fact that Vitamin $\mathrm{K}$ is essential for the carboxylation of both Osteocalcin (bone forming hormone) and Intrinsic Clotting Factors (II,VII, IXand X) a process which takes place in the Liver and without Vitamin $\mathrm{K}$ carboxylation, because of Liver dysfunction following Tissue Scurvy damaged Liver cells, both bone formation and blood clotting are impaired [6].

Carboxylation occurs in the Liver by the action of the enzyme $\gamma$-glutamyl carboxylase which requires Vitamin $\mathrm{K}$ as a cofactor. With impaired Liver function, as shown by the elevated level of ALT and reduced Albumin level in the blood of this child Carboxylation is impaired and fractures and haemorrhage are inevitable.

In assessing the cause of haemorrhage and fractures in children one must obtain a detailed history of the health, nutritional and smoking status of the mother to exclude deficiencies of Vitamin $\mathrm{C}$ and $\mathrm{K}$ and investigate the adequacy of the Liver function of the infant before alleging child abuse [7]. That the child's Liver is dysfunctional is shown by the elevated AST and ALT and reduced level of Albumin and BUN which are tests of Liver function.

\section{Conclusion}

Tissue Scurvy, manifested biochemically by the "strong, specific and consistent" features of hyperglycaemia and abnormal Liver function tests would explain the lesions which doctors misdiagnose as Shaken Baby Syndrome/ Abusive Head Trauma/Inflicted Brain Injury and Nonaccidental Injury. Tests for Tissue Scurvy should be part of the investigation of a childhood illness as Tissue Scurvy manifests itself in other childhood illnesses such as Kawasaki Disease.

\section{Acknowledgements}

I wish to thank the parents of the child for providing me with the Hospital records and giving me permission to publish my findings.

\section{References}

[1] Kalokerinos A. "Every Second Child" Thomas Nelson (Australia) Limited 1974

[2] Innis MD. "Vitamin K Deficiency Disease". Jour of Orthomol Med 2008; vol 23; 15-20

[3] Clemetson CAB. "Vaccinations, Inoculations and Ascorbic Acid". Jour Ortho Mol Med 1999;14:137-142

[4] Innis M D. Autoimmune Tissue Scurvy Misdiagnosed as Child Abuse. Clinical Medicine Research. Vol. X, No. X, 2013.

[5] Cunningham JJ. "The Glucose/Insulin System and Vitamin C: Implications in Insulin-dependent Diabetes Mellitus." J Am Coll Nutr; 1998:vol 17 p105-108

[6] Wallin R Vitamin K-dependent carboxylation and vitamin K metabolism in liver. Effects of warfarin. J Clin Invest > v.76(5); Nov 1985.

[7] Michael D Innis Autoimmunity and non-Accidental Injury in Children Clinical Medicine Research. MM-DD-2013, pp. x-x. doi:10.11648/j.xxx. 